\title{
Laparoscopic intraperitoneal drainage of lymphocele after renal transplantation
}

\author{
Ch. Seiler ${ }^{1}$, F. Horber ${ }^{2}$ and A. Czerniak ${ }^{1}$ \\ ${ }^{1}$ Department of Visceral and Transplantation Surgery, and ${ }^{2}$ Department of Internal Medicine, Inselspital, Bern, Switzerland
}

Key words: kidney transplantation, lymphocele, laparoscopic drainage

\section{Introduction}

The development of a lymphocele after kidney transplantation is a well-recognised complication [1]. Though a variety of non-operative methods are available, laparotomy with transperitoneal internal drainage remains the gold standard for the treatment of lymphocele [2]. With the expanding experience with laparoscopic technique, these lymphatic complications can be managed laparoscopically [3]. We describe laparoscopic drainage of a lymphocele developed after renal transplantation in a patient who has previously had multiple abdominal operations.

\section{Case report}

A 63-year-old woman with end-stage renal disease treated with peritoneal dialysis for 4 years underwent renal transplantation. She has previously had four abdominal operations (catheter-related peritonitis, 2; a gynaecological intervention; and an abdominal wall hernia repair). Renal function normalized after transplantation, but deteriorated after 6 weeks. Computer tomography demonstrated a lymphocele surrounding the lower pole of the transplanted kidney with significant compression of the transplanted ureter (Figure 1). Percutaneous ultrasound-guided drainage of the lymphocele resulted in immediate recovery of kidney function. However, the lymphocele recurred after 7 days. Percutaneous puncture followed by fibrin glue (Tissucol(B) injection was attempted, but the lymphocele recurred within 2 weeks. Percutaneous puncture with installation of $49 \%$ alcohol was also unsuccessful with recurrence after 1 week. At this stage

Correspondence and offprint requests to: Dr Ch. Seiler, Department of Visceral and Transplantation Surgery, Inselspital, 3010 Bern, Switzerland

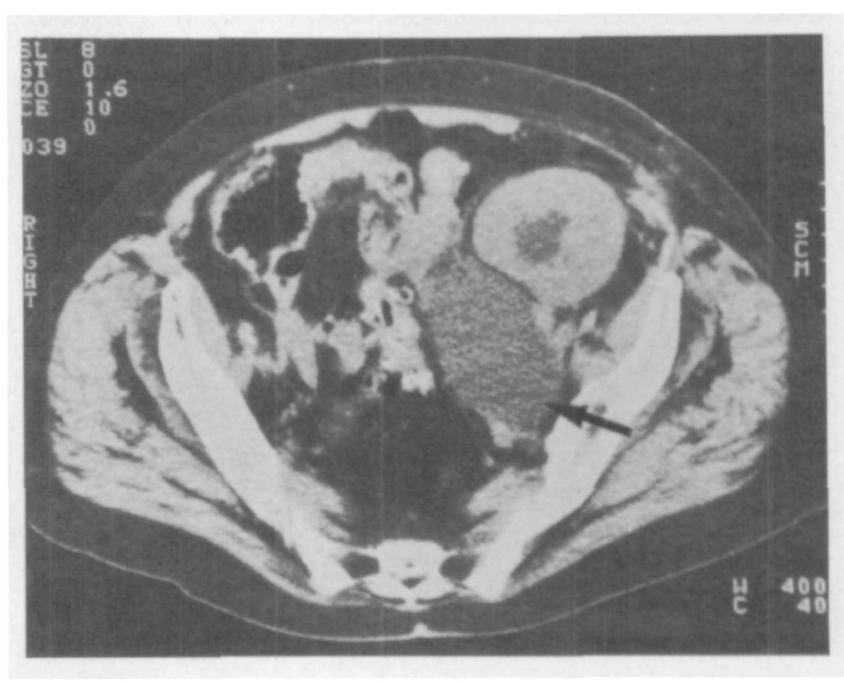

Fig. 1. Computed tomography showing lymphocele at the lower pole of the transplanted kidney (arrow) with dilatation of the renal pelvis.

the patient was referred for a surgical drainage procedure.

We elected to drain the lymphocele laparoscopically and since the patient has had multiple abdominal operations the laparoscopic approach was modified. The first umbilical 10-mm trocar was inserted under direct vision via a $2-\mathrm{cm}$ incision. This aperture was rendered airtight by a purse-string suture. Pneumoperitoneum was thus established and the lymphocele could then be identified as a typical bluish bulge. Two more ports for instrumentation (left midabdomen and right lower abdomen) were created under direct vision. The point of puncture was chosen by compressing the lymphocele with an instrument that produced the typical elastic fluctuations of a fluid-filled cyst. The lymphocele was then punctured with a laparoscopic needle and aspirated. It was then opened longitudinally with a cautery hook and fenestration was performed by removal of a $4 \times 3 \mathrm{~cm}$ piece of the wall (Figure 2a, b). The cyst was then entered with the laparoscope. Inspection and 'palpation' of the internal cyst wall showed no further pathology. Omental pack- 

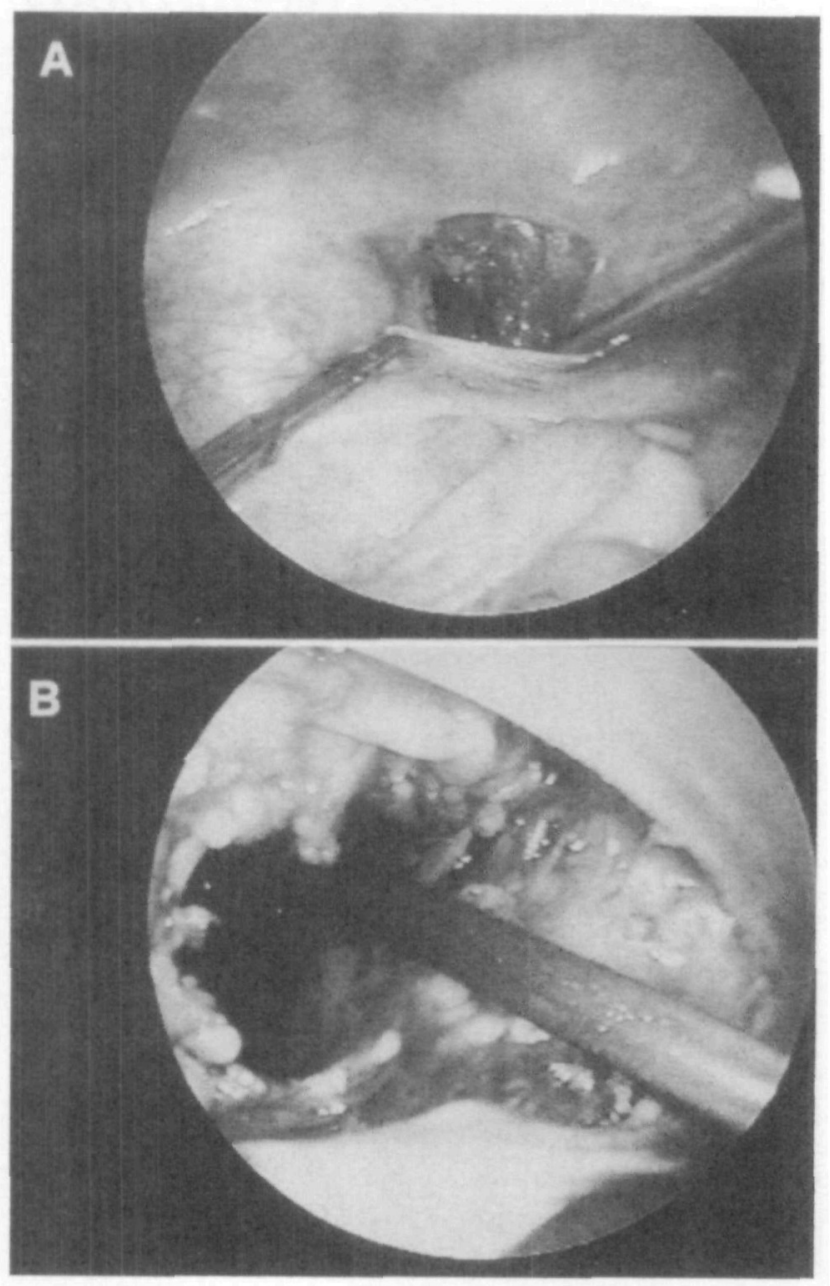

Fig. 2. Laparoscopic view: (a) opening of the lymphocele with the cautery hook; (b) fenestration of the lymphocele completed.

ing could not be performed since the omentum was very short and adherent to the small bowel.

The postoperative course was uneventful and the patient was discharged after 2 days. She was followed up at monthly intervals, and the last follow-up at 8 month demonstrated no clinical or ultrasonographic evidence of recurrence.

\section{Discussion}

The reported incidence of lymphocele following kidney transplantation ranges between 0.6 to $18 \%$ and may result in a significant morbidity [1].

Transperitoneal surgical fenestration of the lymphocele together with insertion of an omental flap into the lymphocele cavity is widely accepted as the preferred treatment of post-transplant lymphocele. By this technique the risk of ureteral, vascular and bowel injury is minimized and the recurrence rate is very low [2].

A variety of non-operative treatment options have been proposed. Needle aspiration may be performed as the first step in the treatment of these lymphoceles, especially when used as a diagnostic modality [4]. However, it is not recommended for the management of large and symptomatic lymphoceles since it is associated with a high recurrence rate as well as possible infectious, and haemorrhagic complications [5], Instillation of povidone-iodine-solution as a sclerosing agent is described but the success rate is rather questionable [6]. Percutaneous insertion of a drainage catheter is also a possibility, but carries a high risk of infection.

Minimal invasive laparoscopic techniques have been found beneficial, particularly with regard to postoperative pain and hospital stay [7]. McCullough et al firstly reported on the use of the laparoscope for intraperitoneal drainage of a post-transplant-lymphocele [3] and four additional cases have been reported [8-11]. We have carried this approach one step further, by using it in a patient who has previously had multiple abdominal operations and peritonitis. In such a situation the laparoscopic approach has to be modified. An infra-umbilical $2-\mathrm{cm}$ incision provides an access to the abdominal cavity sufficient for safe insertion of the first trocar in an airtight fashion by closing the fascial gap with a purse-string suture. Additional ports can then be created and instruments inserted under direct view. Possible adhesions can now be visualized and taken down if necessary. The lymphocele is then visualized and its fluctuating part localized; it is then aspirated and the fenestration procedure performed. An omental packing may be added when possible.

\section{References}

1. Schweizer RT, Cho SI, Koutz SL, Belzer FO. Lymphoceles following renal transplantation. Arch Surg 1977; 104: 42

2. Greenberg BM, Perloff LJ, Grossman RA, Naji A, Barker CF. Treatment of lymphocele in renal allograft recipients. Arch Surg 1985; 120: 501

3. McCullough CS, Soper NJ, Clayman RV, So SS, Jendrisak MD, Hanto DW. Laparoscopic drainage of a posttransplant lymphocele. Transplantation 1991; 51 (3) 725

4. Spigos D, Capek V. Ultrasonographically guided percutaneous aspiration of lymphoceles following renal transplantation: A diagnostic and therapeutic method. J Clin Ultrasound 1975; 4: 45

5. Meyers AM, Levine E, Myburgh JA, Groudie E. Diagnosis and management of lymphoceles after renal transplantation. Urology 1977; 10: 497

6. Gilliland JD, Spres JB, Brown SB, Yrizarry JM, Greenwood LH. Lymphoceles: percutaneous treatment with povidone-iodine sclerosis. Radiology 1989; 171 (1): 227

7. Cuschieri A, Dubois F, Mouriel J et al The European experience with laparoscopic cholocystectomy. Am J Surg 1991; 161: 385

8. Ancona E, Rigotti $P$, Zanino MG, Comandella G, Morpurgo $E$, Costantini M. Treatment of lymphocele following renal transplantation by laparoscopic surgery. Int Surg 1991; 76: 261

9. Voeller G, Butts A, Vera S. Kıdney transplant lymphocele: treatment with laparosopic drainage and mental packing. J Laparoendos Surg 1992; (1): 53

10. Khauli RB, Mosenthal AC, Caushai PF. Treatment of lymphocele and lymphatic fistula following renal transplantation by laparoscopic peritoneal window. J Urol 1992; 147: 1353

11. Mulgaonkar S, Jacobs MG, Viscuso R et al. Laparosocpic internal drainage of lymphocele in renal transplant. Am J Kidney Dis 1992; 19 (5): 490

Recelved: 23.7 .93

Accepted: 18.8 .93 